\title{
A simple method of partial inflation of the LMA cuff before insertion in children to allow cuff pressure without adjustment after insertion
}

\author{
Bo-Eun Moon ${ }^{1}$, Min-Soo Kim ${ }^{1}$, and Jeong Rim Lee ${ }^{1,2}$ \\ ${ }^{1}$ Department of Anesthesiology and Pain Medicine, ${ }^{2}$ Anesthesia and Pain Research Institute, Yonsei University College of Medicine, \\ Seoul, Korea
}

Background: The cuff of the laryngeal mask airway (LMA) is preferred to be partially inflated before insertion in pediatric cases. However, it is not known how much inflation is appropriate. In addition, intra-cuff pressure is not routinely monitored in many institutions despite the fact that a neglected high cuff pressure could cause several complications. This study was conducted to determine whether the cuff inflated with its resting volume before insertion could have a clinically tolerable intra-cuff pressure after insertion.

Methods: One hundred fifty unpremedicated children aged 0 to 9 yrs were enrolled. The pilot balloon valve was connected to a piston-free syringe to keep the valve open to the atmosphere and allowing the pressure within the cuff of to LMA to equalize to atmospheric pressure. Anesthesia was induced with 6 vol\% of sevoflurane in oxygen. After insertion and final positioning of the LMA, the intra-cuff pressure was measured using a cuff pressure manometer.

Results: The mean intra-cuff pressure was $50 \pm 12.9 \mathrm{cmH}_{2} \mathrm{O}$; intra-cuff pressures were 39.1 \pm 9.3, 51.6 \pm 11.2 , and 64.6 $\pm 12.5 \mathrm{cmH}_{2} \mathrm{O}$ for LMAs of sizes 1.5, 2, and 2.5, respectively. Intra-cuff pressure of more than $60 \mathrm{cmH}_{2} \mathrm{O}$ was measured in 26 patients, and the median value was $70 \mathrm{cmH}_{2} \mathrm{O}$. There was weak statistical correlation among age, height, and weight with intra-cuff pressure.

Conclusions: The cuff inflated by the resting volume before insertion may be a simple method for guaranteeing tolerable cuff pressure after insertion. (Korean J Anesthesiol 2012; 62: 524-528)

Key Words: Children, Intra-cuff pressure, Laryngeal mask airway, Resting volume.

Received: October 14, 2011. Revised: 1st, November 23, 2011; 2nd, December 7, 2011. Accepted: December 7, 2011.

Corresponding author: Jeong Rim Lee, M.D., Ph.D., Department of Anesthesiology and Pain Medicine, Anesthesia and Pain Research Institute, Yonsei University College of Medicine, 50, Yonsei-ro, Sinchon-dong, Seodaemun-gu, Seoul 120-752, Korea. Tel: 82-2-2227-3840, Fax: 82-2-22277897, E-mail: MANYA@yuhs.ac

(c) This is an open-access article distributed under the terms of the Creative Commons Attribution Non-Commercial License (http:// creativecommons.org/licenses/by-nc/3.0/), which permits unrestricted non-commercial use, distribution, and reproduction in any medium, provided the original work is properly cited. 


\section{Introduction}

Many pediatric anesthesiologists prefer to insert a laryngeal mask airway (LMA) with partial cuff inflation because the standard Brain's method is not as successful as in adults [1]. In addition, alternative techniques such as lateral or rotational techniques also need partial cuff inflation, which showed higher success rates than the conventional insertion $[2,3]$.

However, it is not known how much the cuff should be inflated and there has been only a suggested "just partially inflation before insertion" [1]. Intra-cuff pressure of the LMA is an important factor with respect to complication and function; neglected high cuff pressure during maintenance can cause several complications including sore throat, dysphasia, or neuropraxia [4-7]. A child's airway is more prone to mucosal damage and swelling than that of an adult $[4,8,9]$. In terms of adequate sealing, intra-cuff pressure should be maintained less than $60 \mathrm{cmH}_{2} \mathrm{O}$ for best sealing [4]. Adjusting intra-cuff pressure is essential in pediatric anesthesia with LMA, but intra-cuff pressures are not routinely monitored in many institutions $[5,8]$. Careless inflation before insertion and lack of adjusting cuff pressure after insertion can deteriorate the performance and cause complications.

Therefore, it would be useful if there were some guidelines for partial cuff which eliminate the necessity of monitoring and adjusting cuff pressure after insertion. Through a small scale clinical study, we found that the resting volume of the cuff can be simply used for partial inflation before insertion, and this may reduce the necessity of adjustment of cuff-pressure after insertion. Therefore, we hypothesize that the cuff inflated with its resting volume would provide allowable intra-cuff pressure after insertion in variable-sized LMA in children.

This study was conducted to determine whether clinically tolerable intra-cuff pressure could be achieved after insertion by simply inflating the cuff with the resting volume prior to surgery.

\section{Materials and Methods}

The study was approved by the hospital's ethics committee. One hundred fifty American Society of Anesthesiologists (ASA) physical status I and II children (0-9 years of age and less than $30 \mathrm{~kg}$ in weight) scheduled for elective inguinal hernia repair undergoing general sevoflurane anesthesia using LMA-classic $\left(\mathrm{LMA}^{\mathrm{TM}}\right.$, The laryngeal mask company Ltd, UK) were included in the present study. Written informed consent was obtained from the parents of each participant. Patients with an abnormal airway, reactive airway disease, and gastroesophageal reflux disease were excluded.

\section{The preparation of LMA}

The LMA size was determined by the manufacturer's guidelines, which suggests a size of 1.5 for $5-10 \mathrm{~kg}$, size 2 for $10-20 \mathrm{~kg}$ and, size 2.5 for $20-30 \mathrm{~kg}$ patients. After routine preinsertion tests of the cuff, the pilot balloon valve was connected to a syringe without a piston to keep the valve open to the atmosphere, and allowing the pressure within the cuff of LMA to equalize with atmospheric pressure (Fig. 1). Before insertion, the syringe was disconnected and the cuff was permitted to remain at its resting volume.

\section{Anesthetic induction and LMA insertion}

All children were not premedicated. Upon arrival at the operating room, patients were monitored with pulse oximetry, capnography, inhaled and exhaled sevoflurane concentrations, noninvasive arterial blood pressure and electrocardiography. Anesthesia was induced using an inhaled technique with 6 vol\% of sevoflurane in oxygen. After loss of consciousness, a peripheral venous cannulation was performed and sevoflurane was adjusted to $3-3.5 \%$ and maintained for several minutes until adequate jaw relaxation was attained for LMA insertion. In previous studies to assess adequate anesthetic depth for LMA insertion in children without neuromuscular blocking agents, the end-tidal sevoflurane concentration was 2.2 to $3.6 \%[10,11]$. Then, we used a $3-3.5 \%$ sevoflurane concentration to abolish the pharyngeal reflex of the patients. The LMA was inserted by lateral or rotational techniques which were described to improve the success rate of LMA insertion in previous studies [1-3]. The successful insertion was confirmed by observing adequate chest wall movement and the presence of a square wave on the capnograph trace during gentle squeezing of the

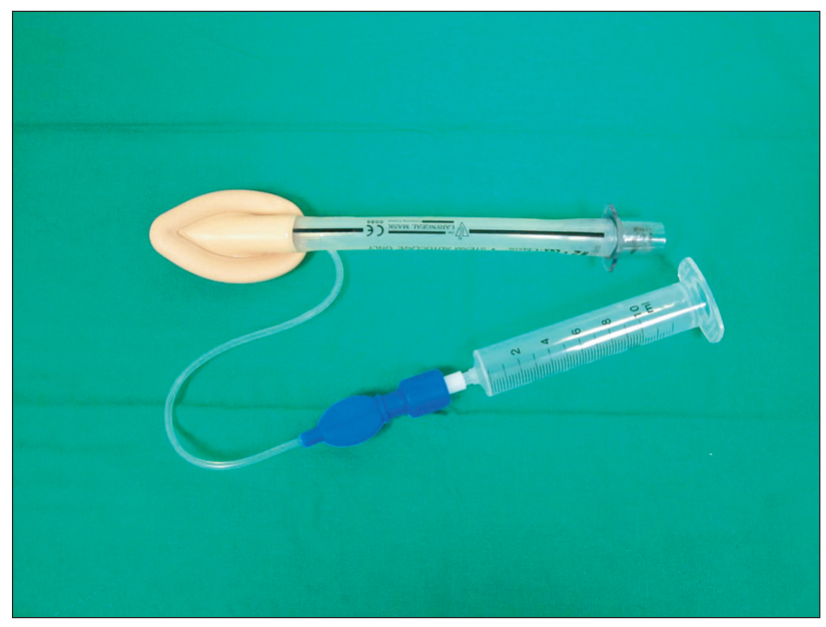

Fig. 1. Preparation of the resting volume as a simple method for partial inflation of the LMA cuff. 
reservoir bag. Inadequate chest wall movement, no wave on the capnograph, less than $4 \mathrm{ml} / \mathrm{kg}$ of exhaled tidal volume, or leakage less than $10 \mathrm{cmH}_{2} \mathrm{O}$ of peak inspiratory pressure were considered as a failed insertion. When insertion failed, reinsertion of the LMA or tracheal intubation was performed. A patient who had a failed LMA insertion after 2 attempts was excluded from this study. After $5 \mathrm{~min}$ of final positioning of the LMA, the intra-cuff pressures were measured using a cuff pressure manometer (Mallinckrodt medical, Athlone, Ireland) three times during $5 \mathrm{~min}$, and the mean of these values was defined as the intra-cuff pressure. After recording the intra-cuff pressure, the cuff pressure was adjusted to below $60 \mathrm{cmH}_{2} \mathrm{O}$ if cuff pressure was more than $60 \mathrm{cmH}_{2} \mathrm{O}$. On the contrary, if intra-cuff pressure was less than $40 \mathrm{cmH}_{2} \mathrm{O}$, cuff pressure was adjusted to $40-60 \mathrm{cmH}_{2} \mathrm{O}$ only when the difference between expiratory tidal volume and inspiratory tidal volume was considerable (i.e more than $1 \mathrm{ml} / \mathrm{kg}$ ).

After collection of study data was accomplished, all recruited patients underwent caudal block with $0.5 \%$ lidocaine $(1 \mathrm{ml} /$ $\mathrm{kg}$, with a maximum of $20 \mathrm{ml}$ ) for perioperative analgesia. Anesthesia was maintained with sevoflurane in $50 \%$ oxygen in air with a total flow rate of $2 \mathrm{~L} / \mathrm{min}$. The sevoflurane concentration was adjusted to $0.8-1.0 \mathrm{MAC}$ in response to clinical signs, and spontaneous ventilation was maintained throughout the anesthetic maintenance of all patients if the tidal volume was more than $6 \mathrm{ml} / \mathrm{kg}$, and the end-tidal $\mathrm{CO}_{2}$ ranged from 35 to $50 \mathrm{mmHg}$ during the procedure. When the operation was finished, the LMA was removed after adequate consciousness and spontaneous respiration was restored. Then the patient was transferred to the recovery room.

\section{Statistical analysis}

Statistical analysis was performed using SPSS 18.0 for Windows (SPSS Inc., Chicago, IL, USA). Data are expressed as median (range) or mean (standard deviation), as appropriate. To compare the differences of the intra-cuff pressure between each LMA size, a one-way analysis of variance (ANOVA) test with a Bonferroni test post-hoc multiple comparisons was used. Correlation analysis was used to find correlations among the age, height and weight of the patients with the intra-cuff pressure. A $\mathrm{P}<0.05$ was considered statistically significant.

\section{Results}

There were no failed insertions; therefore, all patients enrolled in the study were included in the analysis. The patients' characteristics are presented in Table 1.

The mean intra-cuff pressure of all LMA sizes (50.0 \pm 12.9 $\mathrm{cmH}_{2} \mathrm{O}$ ) was lower than $60 \mathrm{cmH}_{2} \mathrm{O}$ (manufacturer's recommendation). The distribution of the intra-cuff pressure for each size of the LMA is shown in Fig. 2. The mean intra-cuff pressures for LMA sizes of 1.5, 2, and 2.5 were $39.1 \pm 9.3,51.6 \pm 11.2$, and 64.6 $\pm 12.5 \mathrm{cmH}_{2} \mathrm{O}$, respectively. In addition, the median values were 40 for LMA size 1.5, 51 for LMA size 2, and $70 \mathrm{cmH}_{2} \mathrm{O}$ for LMA size 2.5. There was one case with LMA size 1.5, fifteen cases with LMA size 2, and ten cases with LMA size 2.5 that had cuff pressures more than $60 \mathrm{cmH}_{2} \mathrm{O}$. Spontaneous ventilation was well maintained in the all recruited children and there was no clinically significant difference between inspiratory-expiratory

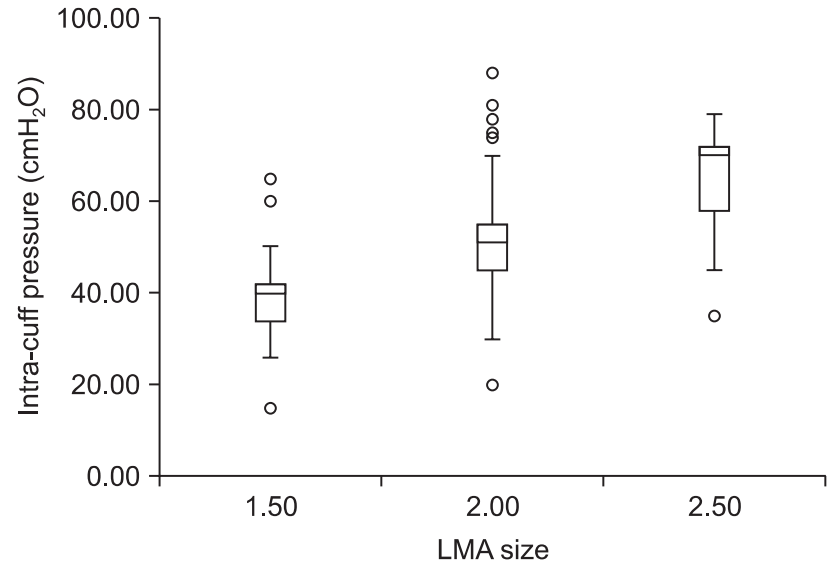

Fig. 2. Distribution of intra-cuff pressure. The box contains the middle $50 \%$ of the data. The upper edge of the box indicates the 75th percentile of the data set, and the lower edge indicates the 25th percentile. The range of the middle two quartiles is known as the inter-quartile range. The ends of the vertical lines indicate the minimum and maximum data values, unless outliers are present in which case the vertical lines extend to a maximum of 1.5 times the inter-quartile range. Any data not included between the vertical lines were plotted as an outlier with a circle. There were significant differences in mean intra-cuff pressure between each LMA size.

Table 1. Patients' Characteristics

\begin{tabular}{|c|c|c|c|c|}
\hline & \multicolumn{3}{|c|}{ LMA size } & \multirow{2}{*}{ Total } \\
\hline & 1.5 & 2 & 2.5 & \\
\hline Number of patients & 34 & 102 & 14 & 150 \\
\hline Age (yr) (mean/SD) & $0.8(0.5)$ & $3.4(1.6)$ & $6.6(1.2)$ & $3.1(2.1)$ \\
\hline Height $(\mathrm{cm})($ mean/SD) & $72.1(12.4)$ & $97.5(16.3)$ & $125.2(7.9)$ & $94.3(20.7)$ \\
\hline Weight (kg) (mean/SD) & $8.4(1.6)$ & $14.5(3.2)$ & $23.4(1.9)$ & $14.0(4.9)$ \\
\hline
\end{tabular}


tidal volume regardless of intra-cuff pressure.

A one-way ANOVA with a Bonferroni post-hoc test for multiple comparisons to compare the differences in intra-cuff pressure between each LMA size, detected significant differences between LMA sizes; mean intra-cuff pressure of LMA size 1.5 was the smallest difference with LMA size 2.5 had the largest difference $\left(39.1 \pm 9.3\right.$ and $\left.64.6 \pm 12.5 \mathrm{cmH}_{2} \mathrm{O}\right)$.

There was weak correlation between the height of patients and the intra-cuff pressure $(\mathrm{r}=0.24, \mathrm{P}=0.003)$. But, there were statistically significant correlations for the age, and weight of the patients with the intra-cuff pressure $(\mathrm{r}=0.31, \mathrm{P}<0.001$, and $\mathrm{r}=$ $0.35, \mathrm{P}<0.001)$.

\section{Discussion}

The present study showed that the mean intra-cuff pressure for pediatric-sized LMAs (1.5, 2, and 2.5) with partial inflation using the resting volume before insertion was $50 \pm 12.9 \mathrm{cmH}_{2} \mathrm{O}$, which is comparable with the manufacturer's recommendation.

A previous investigation in adults made an attempt to apply 'resting volume' of the Portex LMA for partial inflation before insertion. In that study, the mean intra-cuff pressure was 40 $\mathrm{cmH}_{2} \mathrm{O}$ after insertion, and the mean leak pressure was 18.6 $\pm 24.8 \mathrm{cmH}_{2} \mathrm{O}$ [12]. Regarding pediatric patients, von UngernSternberg et al. [13] devised the insertion of the LMA unchanged straight from the sterile package for remaining cuff inflated. They investigated various types of LMAs; and LMAs of the same size did not have identical cuff volumes. For example the variation : in the classic LMA size 2 was, $2-3 \mathrm{ml}, 3-5 \mathrm{ml}$ for size

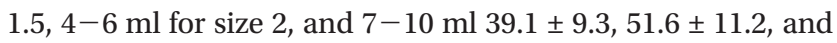
$64.6 \pm 12.5 \mathrm{cmH}_{2} \mathrm{O}$ size 2.5. Though cuff pressures were about $60 \mathrm{cmH}_{2} \mathrm{O}$ for size $1-1.5$ and $44 \mathrm{cmH}_{2} \mathrm{O}$ for size $2-2.5$ in that study, it is cumbersome since the cuff volume of the individual LMA in the sterile pack needs to be remembered and that volume applied each time it is used after sterilization. Therefore, we applied the 'resting volume technique' to pediatric patients, and this technique provided intra-cuff pressure within a tolerable range.

This technique was pursued so there is no need for pressure adjustment after insertion. Regarding criteria for pre-inflation or inflation after insertion, the maximal recommended volume or clinical endpoint may be and option. First, some LMA users inflate the cuff with the maximal recommended volume by the manufacturer; according to the survey by Maino et al. [14], 12 of 30 anesthesiologists use the maximal volume recommended by the manufacturer for inflation after LMA insertion, though 17 of 30 did not use a cuff pressure manometer for cuff pressure monitoring. However, the maximum recommended volume induced high pressure and some pressures were more than 120 $\mathrm{cmH}_{2} \mathrm{O}[8,14]$. Secondly, another technique of cuff inflation after insertion is inflation until a slight outward shift of the device is noted (clinical endpoint) $[4,9]$. However, cuff pressure of all children was more than $60 \mathrm{cmH}_{2} \mathrm{O}$ and the lowest pressure was $92 \mathrm{cmH}_{2} \mathrm{O}$ when using this clinical endpoint [4]. It is known that high cuff pressure is the cause of airway complication by exerting pressure on the laryngeal and pharyngeal structures [5-7]. In addition, the risk of airway swelling is far greater in pediatric patients who have smaller airway diameters compared with adults [8]. Intra-cuff pressure of more than $60 \mathrm{cmH}_{2} \mathrm{O}$ was detected in only $17.3 \%$ of the patients, and the highest intracuff pressure in the present study was $88 \mathrm{cmH}_{2} \mathrm{O}$, which is lower than the lowest value using the clinical endpoint $\left(92 \mathrm{cmH}_{2} \mathrm{O}\right)$ [4]. Therefore, our method may provide less intra-cuff pressure than inflation with maximal cuff volume or by the clinical end-point, giving a tolerable range of intra-cuff pressure within the busy clinical setting.

In the present study, there was a difference in mean intracuff pressure between each LMA size. Intra-cuff pressure of size 1.5 and 2 LMA was about $40 \mathrm{cmH}_{2} \mathrm{O}$ but about $60 \mathrm{cmH}_{2} \mathrm{O}$ for size 2.5 LMA. It is difficult propose the reason for less cuff pressure in smaller LMAs, as the pediatric-sized LMA is a scaled-down version of the adult model [1], so each size may not reflect the growth and size of the pharyngeal space of each weightcategory of children. In addition, there were no functional problems with the use of LMAs sized 1.5 and 2, although intracuff pressure was lower than manufacturer's recommendation. One recent study showed that intra-cuff pressure of $20 \mathrm{cmH}_{2} \mathrm{O}$ and $40 \mathrm{cmH}_{2} \mathrm{O}$ provides better laryngeal seal than $60 \mathrm{cmH}_{2} \mathrm{O}$ [15]. On the contrary, the mean intra-cuff pressure of the 2.5 sized LMA was similar to the manufacturer's recommendation but not sufficiently lower; the number of cases was small and only four cases among 14 had lower cuff pressures than 60 $\mathrm{cmH}_{2} \mathrm{O}$. Further study may be needed for proving the usefulness of the resting volume in the sized 2.5 LMA.

There might be difference of intra-cuff pressure according to use of neuromuscular blocking agent (NMB). In the present study, spontaneous respiration was preserved to abolish the risk of gastric insufflation during positive pressure ventilation via the LMA, so NMB was not administered. NMB may affect intracuff pressure or oropharyngeal leak by changing pharyngeal muscle tone. However, according to the study of Lardner et al. [16] observed leak pressures were similar when NMB was or was not administered.

There were some limitations in the present study. First, the number of cases of the LMA 2.5 was even smaller than other sizes of LMA and there was no case for sized 1 LMA. Second, additional data which reflect laryngeal sealing were not recorded. However, we intended to provide the range of intracuff pressure by our method, and the characteristics could be analogized by the results. Third, we only studied the classic- 
LMA, so there are no data on other types of LMA.

In conclusion, the cuff of LMA with resting volume may be a simple method of pre-inflation for acceptable intra-cuff pressure after insertion. LMA of sizes 1.5 and 2 better obtained the acceptable intra-cuff pressure by this method than size 2.5.

\section{References}

1. Ghai B, Wig J. Comparison of different techniques of laryngeal mask placement in children. Curr Opin Anaesthesiol 2009; 22: 400-4.

2. Ghai B, Makkar JK, Bhardwaj N, Wig J. Laryngeal mask airway insertion in children: comparison between rotational, lateral and standard technique. Paediatr Anaesth 2008; 18: 308-12.

3. Nakayama S, Osaka Y, Yamashita M. The rotational technique with a partially inflated laryngeal mask airway improves the ease of insertion in children. Paediatr Anaesth 2002; 12: 416-9.

4. Licina A, Chambers NA, Hullett B, Erb TO, von Ungern-Sternberg BS. Lower cuff pressures improve the seal of pediatric laryngeal mask airways. Paediatr Anaesth 2008; 18: 952-6.

5. Nott MR, Noble PD, Parmar M. Reducing the incidence of sore throat with the laryngeal mask airway. Eur J Anaesthesiol 1998; 15: 153-7.

6. Brimacombe J, Holyoake L, Keller C, Brimacombe N, Scully M, Barry J, et al. Pharyngolaryngeal, neck, and jaw discomfort after anesthesia with the face mask and laryngeal mask airway at high and low cuff volumes in males and females. Anesthesiology 2000; 93: 26-31.

7. Burgard G, Mollhoff T, Prien T. The effect of laryngeal mask cuff pressure on postoperative sore throat incidence. J Clin Anesth 1996; 8: 198-201.
8. Wallace CJ, Chambers NA, Erb TO, von Ungern-Sternberg BS. Pressure volume curves of paediatric laryngeal mask airways. Anaesthesia 2009; 64: 527-31.

9. Ong M, Chambers NA, Hullet B, Erb TO, von Ungern-Sternberg BS. Laryngeal mask airway and tracheal tube cuff pressures in children: are clinical endpoints valuable for guiding inflation? Anaesthesia 2008; 63: 738-44.

10. Aantaa R, Takala R, Muittari P. Sevoflurane EC50 and EC95 values for laryngeal mask insertion and tracheal intubation in children. $\mathrm{Br}$ J Anaesth 2001; 86: 213-6.

11. Chang CH, Shim YH, Shin YS, Lee KY. Optimal conditions for Laryngeal Mask Airway insertion in children can be determined by the trapezius squeezing test. J Clin Anesth 2008; 20: 99-102.

12. Al-Shaikh B, George William M, Van Zundert AA. Using atmospheric pressure to inflate the cuff of the Portex Laryngeal Mask. Anaesthesia 2005; 60: 296-7.

13. von Ungern-Sternberg BS, Erb TO, Chambers NA, Heaney M. Laryngeal mask airways--to inflate or to deflate after insertion? Paediatr Anaesth 2009; 19: 837-43.

14. Maino P, Dullenkopf A, Keller C, Bernet-Buettiker V, Weiss M. Cuff filling volumes and pressures in pediatric laryngeal mask airways. Paediatr Anaesth 2006; 16: 25-30.

15. Hockings L, Heaney M, Chambers NA, Erb TO, von UngernSternberg BS. Reduced air leakage by adjusting the cuff pressure in pediatric laryngeal mask airways during spontaneous ventilation. Paediatr Anaesth 2010; 20: 313-7.

16. Lardner DR, Cox RG, Ewen A, Dickinson D. Comparison of laryngeal mask airway (LMA)- Proseal and the LMA-Classic in ventilated children receiving neuromuscular blockade. Can J Anaesth 2008; 55: 29-35. 